\title{
SOME RESULTS ABOUT A QUASILINEAR SINGULAR PARABOLIC EQUATION
}

\section{MeHdi BADRA, KaUshiK BAL AND JACQUES GiACOMONI}

Abstract. We investigate the following quasilinear parabolic and singular equation,

$$
\left\{\begin{array}{l}
u_{t}-\Delta_{p} u=\frac{1}{u^{\delta}}+f(x, u) \text { in }(0, T) \times \Omega, \\
u=0 \text { on }(0, T) \times \partial \Omega, \quad u>0 \text { in }(0, T) \times \Omega, \\
u(0, x)=u_{0}(x) \text { in } \Omega,
\end{array}\right.
$$

where $\Omega$ is an open bounded domain with smooth boundary in $\mathbb{R}^{\mathrm{N}}, 1<p<\infty, 0<\delta$ and $T>0$. We assume that $(x, s) \in \Omega \times \mathbb{R}^{+} \rightarrow f(x, s)$ is a bounded below Caratheodory function, asymptotically sub-homogeneous, i.e.

$$
\left\{\begin{array}{l}
\text { if } p \leqslant 2,0 \leqslant \limsup _{t \rightarrow+\infty} \frac{f(x, t)}{t^{p-1}}=\alpha_{f}<\lambda_{1}(\Omega), \\
\text { if } p>2,0 \leqslant \limsup _{t \rightarrow+\infty} \frac{f(x, t)}{t}=\alpha_{f}<\infty,
\end{array}\right.
$$

(where $\lambda_{1}(\Omega)$ is the first eigenvalue of $-\Delta_{p}$ in $\Omega$ with homogeneous Dirichlet boundary conditions) and $u_{0} \in W_{0}^{1, p}(\Omega)$. Then, for any $\delta \in(0,1)$, we prove for any $T>0$ the existence of a weak solution $u \in \mathbf{V}\left(Q_{T}\right)$ to $\left(\mathrm{P}_{\mathrm{t}}\right)$. The proof involves a semi-discretization in time approach and the study of the stationary problem associated to $\left(\mathrm{P}_{\mathrm{t}}\right)$. The key points in the proof is to show that the approximated solutions remain (uniformly) positive in any compact $K$ of $\Omega$ and from energy estimates converges to a weak solution to $\left(\mathrm{P}_{\mathrm{t}}\right)$. Next, under additional assumptions on the initial data, $\delta$ and the nonlinearity $f$, we prove long time convergence of global weak solutions in $W_{0}^{1, p}(\Omega)$. This stabilization property is established by proving an additional energy estimate and by using the regularity result in Simon [23]. These results extend with a different approach a previous work of the authors ([3]) regarding the problem $\left(\mathrm{P}_{\mathrm{t}}\right)$ where existence and uniqueness of solutions are proved under a cone condition on the initial data and via the theory of nonlinear accretive operators.

Mathematics subject classification (2010): 35J65, 35J20, 35J70.

Keywords and phrases: quasilinear parabolic equation, singular nonlinearity, existence of weak solutions, stabilization, time-semi-discretization, Besov spaces.

\section{REFERENCES}

[1] C. ARANDA AND T. GODOY, Existence and multiplicity of positive solutions for a singular problem associated to the p-Laplacian operator, Electron. J. Differential Equations, 132 (2004), 1-15.

[2] R. ARIS, Mathematical modelling techniques, Vol. 24 of Research Notes in Mathematics, Pitman (Advanced Publishing Program), Boston, Mass., 1979.

[3] M. BADRA, K. BAL AND J. GiACOMONI, A singular parabolic equation: existence, stabilization, to appear.

[4] H.T. BANKs, Modeling and control in the biomedical sciences, Vol. 6 Lecture Notes in Biomathematics, Springer-Verlag, Berlin, 1975. 
[5] L. Boccardo AND L. ORsina, Semilinear elliptic equations with singular nonlinearities, Calc. Var. Partial Differential Equations, 37, (3-4) (2010), 363-380.

[6] H. BReZIS, Functional analysis, Sobolev spaces and partial differential equations, Universitext, Springer, New York, 2011.

[7] M.G. Crandall, P.H. Rabinowitz and L. Tartar, On a Dirichlet problem with a singular nonlinearity, Comm. Partial Differential Equations, 2, (2) (1977), 193-222.

[8] J. Dávila And M. Montenegro, Existence and asymptotic behavior for a singular parabolic equation, Trans. Amer. Soc., 357 (5) (2005), 1801-1828.

[9] J.I. DíAz, Nonlinear partial differential equations in free boundaries. Vol. I, volume 106 of Research Notes in Mathematics, Pitman (Advanced Publishing Program), Boston, M.A., 1985.

[10] J.I. DíAZ AND J. E. SAÁ Existence et unicité de solutions positives pour certaines équations elliptiques quasilinéaires, C.R. Acad. Sci. Paris Sér. I. Math., 305 (12) (1987), 521-524.

[11] M. GHERGU AND V.D. RADULESCU, Multi-parameter bifurcation and asymptotics behavior for the singular Lane-Emden-Fowler equation with a convection term, Proc. Roy. Soc. Edinburgh Sect. A, 135, (1) (2005), 61-83.

[12] M. GHERGU AND V.D. RADULESCU, Singular elliptic problems: bifurcation and asymptotic analysis, volume 37 of Oxford Lecture Series in Mathematics and its Applications. The Clarendon Press Oxford University Press, Oxford, 2008.

[13] J. GiACOMOni, I. SCHINDleR AND P. TAKÁČ, Sobolev versus Hölder local minimizers and existence of multiple solutions for a singular quasilinear equation, Ann. Sc. Norm. Super. Pisa Cl Sci. (5), 6, (1) (2007), 117-158.

[14] J. Hernández, F. Mancebo, Singular elliptic and parabolic equations, Handbook of Differential Equations, 3 (2006), 317-400.

[15] J. HeRnÁndez, F. MANCEBo ANd J.M. Vega, On the linearization of some singular, nonlinear elliptic problems and applications, Ann. Inst. H. Poincaré Anal. Non Linéaire, 19, (6) (2002), $777-$ 813.

[16] H.B. Keller AND D.S. CoHEn, Some positone problems suggested by nonlinear heat generation, J. Math. Mech., 16 (1967), 1361-1376.

[17] C.D. Luning AND W.L. PERRY, Positive solutions of negative exponent generalized Emden-Fowler boundary value problems, SIAM J. Math. Anal., 12, (6) (1981), 874-879.

[18] A. NACHMAN AND A. CALlEgARI, A nonlinear singular boundary value problem in the theory of pseudoplastic fluids, SIAM J. Appl. Math., 38, (2) (1980), 275-281.

[19] D. O'Regan, Some general existence principles and results for $\left(\phi\left(y^{\prime}\right)\right)^{\prime}=q f\left(t, y, y^{\prime}\right), \quad 0<t<1$, SIAM J. Math. Anal., 24, (3) (1993), 648-668.

[20] K. Perera AND E.A.B. Silva, On singular p-Laplacian problems, Differential Integral Equations, 20, (1) (2007), 105-120.

[21] W.L. PERRY, A monotone iterative technique for solution of $p$-order $(p<0)$ reaction-diffusion problems in permeable catalysis, J. Comput. Chem., 5, (4) (1984), 353-357.

[22] J. Simon, Régularité de la solution d'un problème aux limites nonlinéaires, Ann. Fac. Sci. Toulouse Math. (5), 3, (3-4) (1981), 247-274.

[23] J. Simon, Compact sets in the space $L^{p}(0, T ; B)$, Ann. Mat. Pura Appl. (4), 146 (1987), 65-96.

[24] P. TAKÁČ, Stabilization of positive solutions for analytic gradient-like systems, Discrete Contin. Dynam. Systems, 6, (4) (2000), 947-973.

[25] H. TRIEBEL, Interpolation theory, functions spaces, differential operators, Johann Ambrosius Barth, Heidelberg, second edition, 1995.

[26] M. WinKLER, Nonuniqueness in the quenching problem, Math. Ann., 339 (3) (2007), 559-597. 